\title{
O Campo Acadêmico da EducaÇão Especial no Brasil ${ }^{1}$ THE ACADEMIC FIELD OF SPECIAL EDUCATION IN BRAZIL
}

\author{
Rosana de Castro CASAGRANDE ${ }^{2}$ \\ Jefferson MAINARDES ${ }^{3}$
}

\begin{abstract}
RESUMO: O objetivo deste trabalho foi analisar a emergência e o desenvolvimento do campo acadêmico da Educaçáo Especial no Brasil. Por meio de uma pesquisa qualitativa, do tipo bibliográfica e documental, foram coletados dois conjuntos de dados: dados históricos e bens acadêmicos, permitindo estruturar a institucionalização do campo acadêmico da Educação Especial em três momentos distintos: a) Elementos antecedentes (de 1789 a 1962); b) Elementos constituintes (de 1962 a 1989); e c) Expansão do campo acadêmico (a partir de 1990). A análise relacional dos dados indicou que a Educação Especial se constitui como um campo acadêmico abrangente e em expansão, porém restrito para a dimensão do país. A caracterização da Educação Especial na qualidade de campo acadêmico possibilitou a sistematização de um conjunto de instâncias de institucionalização responsáveis pela produção e pela divulgação de bens acadêmicos diversos que contribuem significativamente para seu processo de consolidação. Espera-se que os agentes do campo acadêmico atuem na luta contra a invisibilidade e o menosprezo histórico às pessoas com deficiência, por uma Educação Especial Inclusiva no âmbito de uma educação pública, gratuita e de qualidade.
\end{abstract}

PALAVRAS-CHAVE: Educaçăo Especial. Campo acadêmico. Brasil.

\begin{abstract}
The objective of this work was to analyze the emergency and the development of the academic field of Special Education in Brazil. Through a qualitative research, of bibliographic and documentary type, two sets of data were collected: historical data and academic goods, allowing to structure the institutionalization of the academic field of Special Education in three distinct moments: a) Antecedent elements (from 1789 to 1962); b) Constituent elements (from 1962 to 1989); and c) Expansion of the academic field (since 1990). A relational analysis of the data indicates that Special Education is constituted as a broad and expanding academic field, but restricted to the size of the country. The characterization of Special Education as academic field made the systematization of a set of institutionalization bodies responsible for the production and dissemination of diverse academic goods that contribute significantly to its consolidation process possible. It is expected that agents in the academic field will act in the fight against invisibility and historical contempt for people with disabilities, for a Special Inclusive Education within the scope of a free quality public education.
\end{abstract}

KEYWORDS: Special Education. Academic field. Brazil.

\section{INTRODUÇÃo}

O objetivo deste estudo foi abordar a emergência e o desenvolvimento do campo acadêmico da Educação Especial no Brasil a partir da análise de dois conjuntos de dados: históricos e bens acadêmicos ${ }^{4}$, a saber: a) Textos que abordam aspectos histórico-políticos da Educação Especial; b) Textos que circulavam em revistas brasileiras no período de 1893 a 1967, sobre temas voltados à educação das pessoas com deficiência e à Educação Especial; c) Produçóes voltadas ao campo da Educação Especial na Revista Brasileira de Estudos Pedagógicos (RBEP), no período de 1944 a 2018; d) Produçôes sobre a formação de professores para atuação em Educação Especial; e) Cursos de extensão, adicionais e de habilitação em Educação Especial em

\footnotetext{
${ }^{1}$ https://doi.org/10.1590/1980-54702021v27e0132

2 Professora da Universidade Estadual de Ponta Grossa (UEPG). Ponta Grossa/Paraná/Brasil. E-mail: rosanaccasagrande@hotmail. com. ORCID: https://orcid.org/0000-0001-8341-6199

${ }^{3}$ Professor da Universidade Estadual de Ponta Grossa (UEPG). Ponta Grossa/Paraná/Brasil. E-mail: jefferson.m@uol.com.br. ORCID: https://orcid.org/0000-0003-0401-8112

${ }^{4}$ A noção de bens acadêmicos adotada refere-se a: Cursos de Graduação e/ou Pós-Graduação; linhas de pesquisa, grupos e redes de pesquisa, periódicos especializados, associaçóes/entidades científicas; eventos especializados, disciplinas e todas as produçóes e publicaçóes deles provenientes.
} 
Cursos de Pedagogia; f) Programas de Pós-Graduação (lato sensu e stricto sensu) em Educação Especial e Educação; g) Linhas e Grupos de pesquisa em Educação Especial; h) Graduação em Educação Especial nas modalidades presencial e Educação a Distância (EaD); i) Periódicos especializados em Educação Especial; j) Associações científicas (Associação Nacional de PósGraduação e Pesquisa em Educação - ANPEd e Grupo de Trabalho - GT - 15; Associaçáo Brasileira de Pesquisadores em Educaçáo Especial - ABPEE); k) Eventos especializados em Educação Especial; e l) Disciplinas de Educação Especial, Educação Inclusiva e Inclusão nos cursos de Pedagogia; e m) Redes de pesquisa em Educação Especial (Observatório Nacional de Educação Especial [ONEESP], Observatório de Educação Especial [ObEE], Rede de Pesquisa em Educação Especial de Mato Grosso do Sul [REPEEMS], Rede de pesquisadores sobre Financiamento da Educação Especial [FINEESP]).

Por meio de busca realizada nos diretórios de pesquisa (Google Acadêmico; Scientific Electronic Library Online [SciELO], Biblioteca Digital Brasileira de Teses e Dissertaçôes [BDTD], Croosref e Catálogo de Teses e Dissertaçóes da Coordenação de Aperfeiçoamento de Pessoal de Nível Superior [CAPES]), com o uso dos descritores nos títulos e resumos: "campo acadêmico"; "educação especial"; "campo"; "educação especial"; "campo acadêmico"; "campo"; "academic field"; "special education"; e "academic field", encontramos 6.263 produçóes e verificamos a inexistência de pesquisas sobre o campo acadêmico da Educação Especial no Brasil e em língua inglesa. Do total, apenas dez produçóes nacionais (Bernardino, 2007; Brizolla, 2000; Bueno \& Souza, 2018; Bueno et al., 2018; Coppede et al., 2014; Costa, 2014; Manzini \& Glat, 2014; Possa, 2016; Santos, 2017; Silva, 2011; Souza, 2018) continham denominaçóes relacionadas ao termo "campo", dos quais sete utilizaram o termo "campo da Educação Especial", mas sem tratar especificamente do campo acadêmico (Casagrande, 2020). Daí a necessidade de uma pesquisa que caracterize esse campo e destaque sua importância.

Fundamentada em uma perspectiva epistemológica estruturalista, utilizamos como referencial teórico: Pierre Bourdieu, especialmente os conceitos de campo, habitus e capital; institucionalização do campo (Gómez Campo \& Tenti Fanfani, 1989; Suasnábar \& Palamidessi, 2007); conceito de campo teórico (Tello, 2013) e campo acadêmico (Hey, 2008a, 2008b); aspectos metodológicos do campo acadêmico (Stremel, 2016, 2017); fundamentos histórico-políticos e conceituais relacionados à Educação Especial, Inclusão e Educação Inclusiva (Jannuzzi, 2012; Mazzotta, 1982, 1993, 2011). O referencial teórico possibilitou uma análise ampla da Educação Especial e seus conceitos correlatos, situando os agentes no contexto de um campo onde se travam lutas concorrenciais pela autoridade científica, verdade acadêmica e reconhecimento dos pares. O conjunto de aspectos teórico-metodológicos permitiu afirmar que a Educação Especial, no Brasil, constitui-se em um campo acadêmico, com diferentes instâncias de institucionalização, tendo como marco inicial de sua constituição a formação específica de professores para Educação Especial, no âmbito das Universidades brasileiras, a partir da década de 1960. Posteriormente, ocorreu a criação de: habilitação em Educação Especial nos Cursos de Pedagogia; Programa de Pós-Graduação em Educação Especial; Linhas de Pesquisa em Programas de Pós-Graduação em Educação (PPGEs); Grupos de Pesquisa; Cursos de Graduação em Educação Especial; criação de Revistas especializadas; Grupo de Trabalho em associações científicas; associação científica específica; eventos especializados e criação de redes 
de pesquisa. A oferta de disciplinas voltadas à Educação Especial pelas Instituições de Ensino Superior também são elementos que indicam o desenvolvimento do campo.

As referidas instâncias foram classificadas em três momentos de institucionalização, cada qual com sua demarcação histórica: 1) Elementos antecedentes à constituição do campo acadêmico; 2) Elementos constituintes do campo acadêmico; e 3) Expansão do campo acadêmico.

\section{REFERENCIAL TEÓRICO-METODOLÓGICO}

Esta pesquisa caracterizou-se por uma abordagem qualitativa, do tipo documental e bibliográfica, utilizando para organização e sistematização dos dados a Grounded Theory (Corbin \& Strauss, 1990; Prigol \& Behrens, 2019) em articulação com a concepção de análise relacional presente na teoria de campo, de Bourdieu. Com base nos elementos do Enfoque das Epistemologias da Política Educacional (EEPE) apresenta perspectiva epistemológica estruturalista e posicionamento analítico-crítico, estruturada na medida em que se desenvolveram suas diretrizes, embasadas na escolha, no levantamento e no desenvolvimento do referencial teórico, na revisão sistemática da literatura e demais elementos que serviram de fundamento.

O referencial teórico-metodológico escolhido possibilitou uma abordagem de análise que levou em conta a complexidade do objeto. Inicialmente em relação ao conceito de campo como "espaço relativamente autônomo, [...] dotado de leis próprias, representado como espaço estruturado de posiçóes cujas propriedades dependem de sua posição nesses espaços [...]" (Bourdieu, 2003, p. 119). A partir do conceito de campo, consideramos a caracterização da Educação Especial na qualidade de um campo acadêmico, um espaço onde ocorrem práticas sociais distintas, relacionadas à produção e à circulação de bens acadêmicos, o que envolve sobretudo a ideia de universidade (Hey, 2008a, 2008b).

Assim como todo campo, o campo acadêmico constrói sua autonomia e legitimidade por meio de processos de institucionalização (Stremel, 2016, 2017), que, na concepção de Suasnábar e Palamidessi (2007), pode ser definida como os "processos pelos quais certas práticas se recortam como específicas, se regularizam, sancionam e constroem sua autonomia e legitimidade" (p. 41). O grau de diferenciação e de especialização de saberes, de agentes, de instituiçóes, de funções ou de divisóes institucionais que expressa os momentos do campo pode ser analisado como "processos de institucionalização" (p. 41).

Os processos de institucionalização envolvem, portanto, o campo com suas características como estrutura em que se estabelecem relaçóes entre agentes, que formam um habitus próprio. Os agentes do campo acadêmico possuem capitais específicos, podendo ser capital científico, acadêmico e universitário.

Defendemos que a Educação Especial pode ser caracterizada como um campo acadêmico, autônomo e dotado de leis próprias. Seus agentes, constituídos por pesquisadores que produzem e gerenciam bens acadêmicos, desenvolvem um sistema de disposiçóes, geradores de estratégias, por meio do uso de capitais específicos. É um campo de luta concorrencial pela autoridade científica, verdade acadêmica e reconhecimento dos pares. Tal afirmação evidencia-se no processo de produção e de divulgação dos bens acadêmicos dos agentes. Tais afirmaçóes 
corroboram com as concepçóes de Pierre Bourdieu (1974, 1975, 1986, 1989, 2003, 2004a, 2004b) e Bourdieu \& Wacquant (1992).

A emergência do campo acadêmico da Educação Especial situa-se em campos que se sobrepóem e que mantêm estreita relação entre si. O campo político, como sendo de grande abrangência e importância, influencia sobremaneira no desenvolvimento do campo. Aspectos orientadores e legais referentes à Educação Especial encontram-se no âmbito da legislação educacional e do campo específico 5 .

O referencial teórico desta pesquisa, caracterizado especialmente por conceitos de cunho sociológico, possibilitaram a análise relacional e a organização de dois elementos principais pertencentes ao campo acadêmico da Educação Especial, sendo: a) Elementos antecedentes e b) elementos constituintes. Em relação aos elementos antecedentes, tomamos como princípio o campo teórico, ou seja, aquele que surge antes do campo específico propriamente dito - nesse caso, o campo acadêmico. Compreendemos campo teórico no sentido de "homologado ao campo acadêmico [...], [...] a partir desse campo é produzido conhecimento (pesquisa), [...] circulação de conhecimento [...] e uso ou aplicação desse conhecimento" (Tello, 2013, p. 66); dessa forma, os conhecimentos anteriores ao estabelecimento do campo acadêmico são responsáveis pela circulação do conhecimento, o que conduzirá e influenciará na dinâmica teórico-prática, determinando o modo como serão aplicados no contexto.

Em relação aos elementos constituintes do campo acadêmico, estes foram elencados a partir de indicativos destacados por Gómez Campo e Tenti Fanfani (1989) e Suasnábar e Palamidessi (2007) ao se referirem a periódicos, associações, reuniōes técnicas e científicas e às cátedras universitárias. Além desses elementos, consideramos também indicativo de institucionalização do campo acadêmico da Educação Especial: as habilitaçóes e os Cursos de Graduação na modalidade presencial e EaD; os Programas de Pós-Graduação em Educação e Educação Especial; os Grupos e Linhas de pesquisa; os Eventos especializados e as Redes de pesquisas. O estudo do campo acadêmico é desafiador, pois implica a organização e a sistematização de uma série de dados, que, somente em conjunto e na conjuntura relacional, refletirão ou não sua existência.

\section{Metodologia}

Trata-se de uma pesquisa de abordagem qualitativa, do tipo bibliográfica e documental. Os dados quantitativos e qualitativos foram organizados por meio da Grounded Theory ou Teoria Fundamentada em Dados (TFD), o que possibilitou a análise do objeto em suas

\footnotetext{
${ }^{5}$ Citamos como exemplos: Constituição Federal de 1988; Lei de Diretrizes e Bases da Educação (LDBN) - Lei no 9.394 , de 20 de dezembro de 1996; Diretrizes Nacionais para a Educação Especial na Educação Básica - Resolução no 2, de 11 de setembro de 2001; Política Nacional de Educação Especial na Perspectiva da Educação Inclusiva (2008); Resolução no 4, de 2 de outubro de 2009, que instituiu as diretrizes operacionais para o Atendimento Educacional Especializado na Educação Básica, modalidade de Educação Especial; Diretrizes Curriculares Nacionais da Educação Básica (2013), em que está inserto o documento Diretrizes Operacionais para o Atendimento Educacional Especializado na Educação Básica, modalidade Educação Especial, com base na Política Nacional de Educação Especial na Perspectiva da Educação Inclusiva (2008); Nota técnica no 4, de 2014, com orientaçôes quanto a documentos comprobatórios de alunos com deficiência, transtornos globais do desenvolvimento e altas habilidades/ superdotação no Censo Escolar; e a Lei no 13.146, de 6 de julho de 2015, que instituiu a Lei Brasileira de Inclusão da Pessoa com Deficiência (Estatuto da Pessoa com Deficiência); Portaria no 243, de 15 de abril de 2016. Além disso, no dia 30 de setembro de 2020, foi aprovada, pelo Conselho Nacional de Educação (CNE), a Política Nacional de Educação Especial, Equitativa, Inclusiva e ao longo do tempo (2020). Atualmente, há uma intensa discussão no campo acadêmico sobre a constitucionalidade das mudanças propostas na versão desse último documento.
} 
múltiplas instâncias, tendo em vista a complexidade das relações estabelecidas entre os agentes e as circunstâncias histórico-políticas nas quais os elementos da constituição do campo se configuraram, acoplada à análise relacional e à concepção bordieusiana de campo, habitus e capital. A TFD possui encaminhamentos e procedimentos específicos para coleta e análise de dados, que consideram: a) a inter-relação entre coleta e análise dos dados; b) a utilização de comparaçóes e relaçóes constantes; c) a incorporação do processo à teoria; e d) a análise de condiçóes estruturais mais amplas, sem menosprezar a pesquisa microscópica (Corbin \& Strauss, 1990).

Concordamos com as concepçóes de Bourdieu et al. (2007), ao considerarem que o objeto de estudo se desenvolve em paralelo ao próprio estudo. Nesse contexto, os elementos desta pesquisa foram sendo verificados, organizados e analisados em conformidade com a dinâmica dos achados e com os pressupostos contextuais (Prigol \& Behrens, 2019).

Tendo em vista a interface da Educação Especial com outras áreas do conhecimento, com as quais mantém estreita relação, detivemo-nos na análise do campo acadêmico no âmbito educacional, de modo a destacar os elementos antecedentes e constituintes do campo acadêmico, agrupados em um conjunto de itens de pesquisa, composto por fontes de pesquisa documental e bibliográfica estruturadas metodologicamente com adaptaçóes da proposta de Stremel $(2016,2017)$ para análise do campo acadêmico da Política Educacional no Brasil. A coleta de dados foi realizada por meio de:

a) acesso a reunióes da ANPEd (da 12a a 38 ) por meio do site e de discos compactos (CDs);

b) documentos impressos: livros, artigos diversos, números da Revista Brasileira de Estudos Pedagógicos (RBEP) a partir de 1944;

c) documentos da internet: sites de todas as Instituiçóes de Ensino Superior (IES) públicas brasileiras para acesso aos Projetos Políticos Pedagógicos e Matrizes Curriculares dos Cursos de Pedagogia; artigos, teses, dissertações; fontes documentais do Repositório da Universidade Federal de Santa Catarina (UFSC); sites dos Grupos de Pesquisa (ONEESP, ObEE; REPEEMS e FINEESP); ABPEE; Reuniōes da ANPEd; Eventos especializados; Plataforma Lattes, a fim de coletar dados dos pesquisadores; de órgãos governamentais (Ministério da Educação [MEC], e-MEC, Plataforma Sucupira, Conselho Nacional de Desenvolvimento Científico e Tecnológico [CNPq], CAPES, Instituto Nacional de Estudos e Pesquisas Educacionais Anísio Teixeira [INEP]) e e-mails de coordenadores de projetos, grupos e redes de pesquisa.

Para organização e sistematização dos dados, foi usado o editor de planilhas Microsoft Excel do Sistema Operacional Microsoft Windows e ferramentas do Acrobat Reader DC. A análise dos dados foi realizada levando-se em conta a "sensibilidade teórica" e por meio dos processos de codificação aberta e axial da TDF, combinada à análise relacional e à noção de "campos abertos" (Bourdieu, 1989; Bourdieu \& Wacquant, 1992). A codificação aberta permitiu a identificação de conceitos a partir das ideias centrais contidas nos dados, sendo examinados, comparados por similaridades e diferenças e categorizados. A codificação axial consistiu na relação das categorias às subcategorias, reorganização e redução dos dados, na busca pela ideia central (Corbin \& Strauss, 1990). 
No que se refere à perspectiva de análise relacional, Bourdieu (1989) deixou claro que o significado de relacional está atrelado à filosofia da ciência, que atribui primazia às relaçóes estabelecidas entre os agentes. A perspectiva relacional impóe-se ao senso comum e à perspectiva substancial da realidade. Para Bourdieu (1989), o "real é relacional" (p. 6), e essa afirmação previne leituras substancialistas - leituras em si e por si mesmas -, daí a necessidade de que a análise dos dados seja realizada a partir do seu contexto sócio-histórico, político, econômico, cultural e educacional.

Como anteriormente mencionado, a análise do campo acadêmico demandou a pesquisa de diversas fontes e itens, organizados e sistematizados, por ordem cronológica. No Quadro 1 a seguir, estâo descritos os conjuntos de dados analisados: dados históricos e bens acadêmicos, em relação aos itens de pesquisa, período analisado, fonte e período selecionado.

\section{Quadro 1}

Elementos constituintes do campo acadêmico da Educação Especial: descrição dos itens, fonte e período analisados e selecionados

\begin{tabular}{|c|c|c|}
\hline \multirow{6}{*}{ 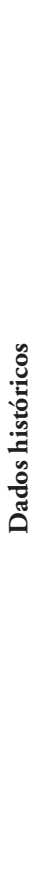 } & Item de pesquisa e período & Fonte e período selecionado \\
\hline & $\begin{array}{l}\text { Produçóes sobre história da pessoa com } \\
\text { deficiência a partir de } 1789 \text {. }\end{array}$ & $\begin{array}{l}\text { Teixeira (1968); Jannuzzi (1985, 2012); Kirk e Gallagher (1987); } \\
\text { Mazzotta (1982, 1994, 1996, 2011); Bueno, (2004); Sassaki (1997); } \\
\text { Glat (1995, 2013); Glat e Fernandes (2005); Romero (2006). Legis- } \\
\text { lação brasileira (1961 a 2020). }\end{array}$ \\
\hline & $\begin{array}{l}\text { Revistas de Educação em circulação no } \\
\text { Brasil: } 368 \text { ediçóes no período de } 1893 \\
\text { a } 1967 .\end{array}$ & $\begin{array}{l}\text { Repositório da Universidade Federal de Santa Catarina: Foram se- } \\
\text { lecionadas } 22 \text { produçóes referentes à pessoa com deficiência, publi- } \\
\text { cadas no período de } 1903 \text { a 1960: Puigarri (1903); Poiry (1925); } \\
\text { Doria (1927); Rabello (1928); Souza Pinto (1933, 1935a, 1935b, } \\
\text { 1935c, 1937, 1950, 1959); Carvalho (1946); Giúdice (1954); Ciulla } \\
\text { (1947); Plata (1948); Pourchet (1956); Rocha Filho (1957) e Costa } \\
\text { (1957); Okoniewski (1957); Menucci (1960); e Castiglioni (1960). }\end{array}$ \\
\hline & Bibliografia Pedagógica Brasileira & INEP (1944). De 1812 a 1900 \\
\hline & $\begin{array}{l}\text { Produçốes sobre a história da formaçấo } \\
\text { de professores antes da constituiçấo do } \\
\text { campo acadêmico. }\end{array}$ & $\begin{array}{l}\text { Livros, artigos e legislação no site do MEC: (Lei no } 9.394 \text { 1996; } \\
\text { Resolução no 2, 2001; Lei no 13.146, 2015; Instituto Benjamin } \\
\text { Constant, 2020; Ribeiro (1942); Mazzotta (1993); Almeida (2004); } \\
\text { Jannuzzi (2012); Bentes (2010); Oliveira \& França (2019). }\end{array}$ \\
\hline & $\begin{array}{l}\text { Revista Brasileira de Estudos Pedagógicos, } \\
\text { de } 1944 \text { a } 2018 .\end{array}$ & $\begin{array}{l}\text { Textos (n=37) sobre deficiência e Educação Especial, no período de } \\
1946 \text { a } 2018 \text {. }\end{array}$ \\
\hline
\end{tabular}




\begin{tabular}{|c|c|c|}
\hline \multirow{10}{*}{ 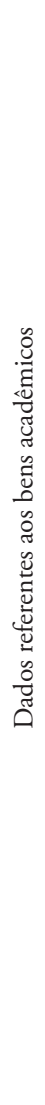 } & $\begin{array}{l}\text { Formação de professores. Primeiros cursos } \\
\text { voltados à Educaçáo Especial ofertados } \\
\text { em Instituiçóes de Ensino Superior (pú- } \\
\text { blicas e privadas). }\end{array}$ & $\begin{array}{l}\text { Livros (Mazzotta, 1993); Michels (2017). } \\
\text { Sites da Universidade Federal de Santa Maria (UFSM, 2019) e Uni- } \\
\text { versidade Federal de Sáo Carlos (UFSCar), ano de } 2019 .\end{array}$ \\
\hline & Curso de Pós-Graduação. & Site da Universidade Federal de São Carlos (UFSCar, 2019). \\
\hline & $\begin{array}{l}\text { Linhas de pesquisa em Programas de } \\
\text { Pós-Graduação em Educação e Educação } \\
\text { Especial, Inclusão e Educação Inclusiva. }\end{array}$ & $\begin{array}{l}\text { Cadernos de Indicadores, Plataforma Sucupira e sites das Instituiçóes } \\
\text { de Ensino Superior, nos anos de 2007, } 2012 \text { e } 2018 .\end{array}$ \\
\hline & $\begin{array}{l}\text { Cursos de Graduação em Educação Espe- } \\
\text { cial (presenciais e EaD). }\end{array}$ & Plataforma e-Mec, no ano de 2019. \\
\hline & $\begin{array}{l}\text { Grupos de Pesquisa em Educação Especial } \\
\text { no Brasil. }\end{array}$ & $\begin{array}{l}\text { Site do Diretório de Grupos de Pesquisa no Brasil (CNPq) de agosto } \\
\text { a outubro de } 2019 \text {. }\end{array}$ \\
\hline & $\begin{array}{l}\text { Cursos de Especializaçáo Lato sensu em } \\
\text { Educação Especial. }\end{array}$ & Plataforma e-Mec, no ano de 2019. \\
\hline & $\begin{array}{l}\text { Periódicos especializados em Educação } \\
\text { Especial. }\end{array}$ & Plataforma Sucupira: Qualis 2013/2016 e Qualis Provisório 2019. \\
\hline & Revista Brasileira de Educação Especial. & $\begin{array}{l}\text { Site da Associação Brasileira de Pesquisadores em Educação Especial } \\
\text { (ABPEE), de } 1992 \text { a 2005. Site da SciELO, a partir de } 2005 .\end{array}$ \\
\hline & $\begin{array}{l}\text { Associações científicas de Educação } \\
\text { Especial. }\end{array}$ & $\begin{array}{l}\text { Artigos (Carvalho, 1988; Manzini et al., 2009; Masini, 2011; Ferrei- } \\
\text { ra \& Bueno, 2011). CDs, material impresso e site da ANPEd - GT } \\
15^{6} \text {, da } 12^{\text {a }} \text { a } 38^{\text {a }} \text { Reunião (1989 a 2017). }\end{array}$ \\
\hline & $\begin{array}{l}\text { Eventos }^{7} \text { especializados em Educação Es- } \\
\text { pecial. Congresso Brasileiro de Educaçãoo } \\
\text { Especial (CBEE). }\end{array}$ & $\begin{array}{l}\text { Congresso Brasileiro de Educaçáo Especial (CBEE) (do I ao VIII), } \\
\text { de } 2003 \text { a } 2018 \text {. Pesquisa individual nos sites do evento, no período } \\
\text { de } 2003 \text { a } 2018 \text {. }\end{array}$ \\
\hline
\end{tabular}

Com base nos conjuntos de itens analisados, foi possível organizar os elementos antecedentes e constituintes do campo acadêmico da Educação Especial no Brasil, em momentos demarcados historicamente, conforme Quadro 2.

\footnotetext{
${ }^{6}$ Grupo de Trabalho de Educação Especial.

${ }^{7}$ Foram considerados outros eventos abrangentes: Congresso Nacional de Educação Especial e Inclusão (CONEESPI); Congresso Nacional de Práticas Inclusivas (CONAPI); Congresso Brasileiro Multidisciplinar de Educação Especial; Seminário Nacional de Educação Especial (SENACE); Encontro Nacional de Pesquisadores em Educação Especial e Inclusão Escolar (ENPEI); Congresso Internacional de Educação Especial e Inclusão; e Congresso Internacional de Educação Inclusiva (CINTEDES).
} 


\section{Quadro 2}

Elementos antecedentes e constituintes do campo acadêmico da Educação Especial no Brasil e sua cronologia

\begin{tabular}{|c|c|c|c|}
\hline & $\begin{array}{c}\text { Elementos antecedentes do campo } \\
\text { acadêmico }\end{array}$ & $\begin{array}{l}\text { Elementos constituintes do campo } \\
\text { acadêmico }\end{array}$ & Demarcação histórica \\
\hline 1 & Tentativas de institucionalização & - & 1789 \\
\hline 2 & $\begin{array}{l}\text { Marcos da institucionalização da Educaçáo } \\
\text { Especial }\end{array}$ & - & 1854 e 1857 \\
\hline 3 & Textos em revistas brasileiras & - & A partir de 1893 \\
\hline 4 & Textos publicados na RBEP & - & A partir de 1944 \\
\hline 5 & - & $\begin{array}{l}\text { Formação de professores para atuação na } \\
\text { Educaçáo Especial. }\end{array}$ & 1962 \\
\hline 6 & - & $\begin{array}{l}\text { Habilitação em Educação Especial nos } \\
\text { Cursos de Pedagogia. }\end{array}$ & $1972^{8}$ \\
\hline 7 & - & $\begin{array}{l}\text { Programa de Pós-Graduação em Educa- } \\
\text { ção Especial da UFSCar. }\end{array}$ & 1978 \\
\hline 8 & - & $\begin{array}{l}\text { Curso de Educação Especial - Licen- } \\
\text { ciatura Plena, com Habilitaçáo em } \\
\text { Deficientes Mentais e Deficientes da } \\
\text { Audiocomunicação na UFSM. }\end{array}$ & 1982 \\
\hline 9 & - & Grupo de Pesquisa. & 1985 \\
\hline 10 & - & Revista Educação Especial da UFSM. & 1987 \\
\hline 11 & - & GT 15 da ANPEd. & 1989 \\
\hline 12 & - & $\begin{array}{l}\text { Associação Brasileira de Pesquisadores } \\
\text { em Educaçấo Especial. }\end{array}$ & 1993 \\
\hline 13 & - & $\begin{array}{l}\text { Eventos especializados - Congresso } \\
\text { Brasileiro de Educação Especial. }\end{array}$ & 2003 \\
\hline 14 & - & $\begin{array}{l}\text { Redes de pesquisa/açôes interinstitu- } \\
\text { cionais. }\end{array}$ & 2005 \\
\hline
\end{tabular}

\section{Resultados}

A análise dos conjuntos de dados, histórico e bens acadêmicos possibilitou a estruturação de três momentos da constituição do campo acadêmico da Educação Especial, no Brasil. De modo geral, podemos sistematizar a institucionalização desse campo em três momentos: a) Elementos antecedentes (de 1789 a 1962); b) Elementos constituintes (de 1962 a 1989); e c) Expansão do campo (a partir de 1990), descritos na sequência.

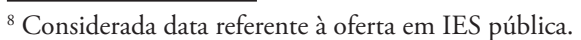




\subsection{Primeiro momento: elementos antecedentes À constituiçáo do Campo ACADÊMICO}

A demarcação histórica do primeiro momento, de 1789 a 1962, revela os elementos antecedentes que influenciaram a institucionalização do campo acadêmico. Esse momento incluiu a análise de: a) Produçóes sobre história da pessoa com deficiência; b) Textos ( $n=22)$ que circulavam em Revistas Nacionais de Educação, no período de 1893 a 1960; c) Bibliografia Pedagógica Brasileira, de 1812 a 1900; d) Produçóes sobre o histórico da formação de professores antes da constituição do campo acadêmico; d) Textos (n=37) publicados na RBEP a partir de 1944 .

O marco inicial desse momento foram as tentativas de institucionalização da Educação Especial, derivadas de movimentos histórico-políticos, evidentes, no Brasil, no fim do século XVIII e começo do XIX, em movimentos como a Inconfidência Mineira (1789), a Conjuração Baiana (1798) e a Revolução Pernambucana (1817) (Jannuzzi, 2012). Houve, nesse contexto, a uniáo de ideais de um grupo de profissionais formados por médicos, advogados, soldados, alfaiates, entre outros, que faziam parte de um movimento liberal denominado de "liberalismo de elite", "limitado pela aceitação da escravidão", mas que "lutou pela abolição de algumas instituiçóes coloniais, criticou o dogmatismo e o poder autocrático, se opôs à interferência do Estado na economia, defendeu a liberdade de expressão e a propriedade privada” (p. 6). Essa luta contribuiu, mesmo que de maneira tímida, como tentativas iniciais de atenção à Educação das pessoas com deficiência.

Desde o período Imperial circulam Revistas de Educação no Brasil, com denominaçóes diversas. Ao analisarmos 368 edições dessas revistas, encontramos, no período de 1893 a 1967, 22 textos que classificamos em: 1. Textos de expressão de ideais políticos e particulares; e 2. Textos de expressão científica de abordagem empírico-analítica. Os primeiros retratavam a concepção de deficiência da época, revelando preconceito, descaso e desatenção, bem como a predominância do discurso político indireto, com algumas concepçóes contrárias. Os textos revelam o entrelaçamento dos campos político, econômico, religioso e educacional do País, envolvidos com as perspectivas pessoais dos autores, que Tello (2013, p. 13) denomina de "posição epistemológica do pesquisador".

Nesse período analisado, que denominamos de campo teórico (Tello, 2003), as produçóes textuais eram impregnadas pelos termos "anormal" e "anormalidade" e refletiam uma perspectiva histórica que levava em conta a falta de ajustamento da pessoa com deficiência na sociedade, também pautada por valores econômicos, políticos, culturais e religiosos, que identificavam o "normal" como superior e o "anormal" como inferior. Os textos de abordagem empírico-analista surgiram a partir de 1948, com o texto de autor José Plata, que escreveu para a RBEP, um texto com o título $A$ capacidade dos cegos para a sintese imaginativa espacial.

As produções sobre Educação Especial, do período de 1944 a 1960, publicadas na RBEP, também evidenciaram as condiçóes histórico-políticas da Educação Especial. Considerada, inicialmente, como um meio de propagação da estrutura que a gerou, a produção e o acesso às publicaçóes da RBEP pelos agentes do campo acadêmico influenciaram e influenciam diretamente na constituição do habitus do campo acadêmico da Educação Especial. Sob a tutela do INEP, criado em 1937, e considerada publicação oficial do MEC, a partir de 1944, a RBEP surgiu, originalmente, na intenção de divulgar as pesquisas nas áreas de biologia, psi- 
cologia e sociologia educacional; todavia, transformou-se, posteriormente, em um símbolo da divulgação científica, abarcando pesquisas de diversos âmbitos e áreas.

No período final da década de 1970 e no início da de 1980, o INEP passou por transformaçóes significativas, fazendo com que a revista adquirisse maior autonomia na divulgação do conhecimento científico, ao incorporar-se aos Programas de Pós-Graduação, que iniciavam seu desenvolvimento no Brasil. O movimento efervescente dos educadores, aliado à realização das primeiras Conferências de Educação no Brasil organizadas pela ANPEd, Sindicato Nacional dos Docentes das Instituiçóes de Ensino Superior [Andes] e Centro de Estudos Educação e Sociedade [Cedes], traduz o cenário da revista e suas produçóes na década de 1980. A RBEP passou por um longo período (até o número 146, no ano de 1983) sem a composição de um corpus científico, sendo

o caráter dominante da Revista [...] o de órgão oficial que se dedicava à divulgação das políticas, projetos e ideias do MEC. Nessa condiçấo, a Rbep era composta com material elaborado ou solicitado pelos próprios dirigentes do Inep. A partir do no 147 , de maio/ago. 1983, ela passa a receber colaborações oriundas dominantemente da comunidade acadêmica, apresentando as normas de publicação e contando com a colaboraçáo de consultores para avaliar os textos recebidos. (Saviani, 2012, p. 310)

Outro elemento importante que antecedeu a institucionalização do campo acadêmico foi a formação para atuação em Educação Especial. As leituras sobre o tema nos conduziram à certificação de que a formação para atuação na Educação Especial iniciou bem antes da institucionalizaçáo do campo acadêmico. Considerados marcos institucionais da Educação Especial, o Imperial Instituto dos Meninos Cegos e o Instituto Imperial dos Meninos Surdos selecionavam seus alunos, que passavam, posteriormente, a professores. Tendo passado por diversas mudanças, o Instituto Nacional de Surdos-Mudos instituiu, por meio do regimento de 1911, o Curso Normal direcionado a instrutores de surdos mudos e à criação do internato feminino (Ribeiro, 1942). A formação de profissionais para trabalho docente na Educação Especial aconteceu de maneira tardia e lenta no Brasil, tendo "progredido" para especialização em nível médio somente na década de 1950, graças à preocupação dos mesmos institutos de cegos e surdos e outros de iniciativa privada.

Os elementos aqui assinalados e caracterizados como antecedentes à institucionalização do campo acadêmico da Educação Especial influenciaram sua institucionalização.

\subsection{SEgUNDO MOMENTO: ELEMENTOS CONSTITUINTES DO CAMPO ACADÊMICO}

O segundo momento, que indica os elementos constituintes do campo acadêmico da Educação Especial, iniciou-se em 1962 com a formação de professores de Educação Especial na UFSM, até o ano de 1989, com a criação do GT 15 da ANPEd (UFSM, 2019). Os elementos constituintes são: A formação de professores para a atuação em Educação Especial, por meio de cursos de extensão (1962) e cursos adicionais (1964); Habilitação em Educação Especial nos cursos de Pedagogia em IES particular (1972) e pública (1974); Pós-Graduação em Educação Especial da UFSCar, sendo: Mestrado (1978) e Doutorado (1999) e as de Linhas de Pesquisa em Educação Especial, Inclusão e Educação Inclusiva em Programas de Pós-Graduação em 
Educação; Criação da Graduação em Educação Especial na UFSM (1982); Grupo de Pesquisa em Educação Especial (1985); Revista Educação Especial (1987) e GT 15 da ANPEd (1989).

Esse importante momento aponta para o marco inicial da institucionalização do campo da Educação Especial no Brasil - quando a Educação Especial passa a ser tratada em âmbito universitário. No ano de 1962, a UFSM passou a ofertar cursos de extensão e adicionais com foco na formação de professores para atuação na Educação Especial, demarcando a representatividade e a importância dessa instituição no estabelecimento do campo acadêmico, o que se revela durante todo seu percurso de institucionalização e expansão (UFSM, 2019).

O surgimento da habilitação em Educação Especial foi na década de 1970. No ano de 1972, no município de Franca (SP), surgiu o primeiro curso de formação de professores de "excepcionais", na área de ensino de Deficiência Mental, como habilitação do curso de Pedagogia, na Faculdade Pestalozzi de Ciências, Educação e Tecnologia (Mazzotta, 1993). Em 1973, o Colégio Universitário da Universidade Mackenzie ofertou, no curso de Pedagogia, a habilitação para o "magistério de deficientes mentais". No mesmo ano, a Pontifícia Universidade Católica de São Paulo e as Faculdades Metropolitanas Unidas ofertaram habilitação em "educação de deficientes da Audiocomunicação". No ano de 1975, a Pontifícia Universidade Católica de Campinas passou a ofertar o curso de Pedagogia, com habilitação em "magistério de deficientes mentais". Na Faculdade Auxilium de Filosofia, Ciências e Letras (Cidade de Lins), havia oferta de habilitação em "magistério para deficientes mentais" e, na Universidade de Mogi das Cruzes, o Curso de "Magistério para Deficientes da Audiocomunicação", ambas em 1976 (Mazzotta, 1993).

Outro elemento constituinte importante da Educação Especial surgiu no ano de 1978, na UFSCar, com a oferta do curso de Mestrado pelo Programa de Pós-Graduação em Educação Especial. O Programa de Mestrado em Educaçáo Especial (PMEE) teve três reformulações, em 1986, 1990 e 1997, e passou a ofertar curso de Doutorado no ano de 1999. O surgimento do Programa de Pós-Graduação em Educação Especial, antecedente ao Curso de Graduação em Educação Especial, justificou-se pela necessidade de demanda profissional para atuação na formação inicial (UFSCar, 2019). Apesar do Programa de Pós-Graduação em Educação Especial ter surgido em 1978, no início dessa década era possível encontrar produçóes em nível de Mestrado em Programas de Pós-Graduação em Educação (Silva, 2018).

No ano de 1982, surgiu o Curso de Educação Especial Licenciatura Plena com habilitação em Deficientes Mentais e da Audiocomunicação, aprovado na UFSM, por meio do Parecer no 65/1982. Até 2008, a UFSM foi a única IES pública a ofertar gratuitamente o curso presencial de Educação Especial (UFSM, 2019).

Constatamos que, no ano de 2018, havia 265 grupos de pesquisas sobre Educação Especial no Brasil, em sua maioria formado por pesquisadores das regióes Sudeste e Sul do Brasil. O grupo mais antigo encontrado iniciou em 1985 sob a coordenação da Profa. Dra. Maria Piedade da Costa. Há um número expressivo de grupos de pesquisa com os termos Inclusão e Educação Inclusiva na denominação de suas linhas de pesquisa e repercussões. Concluímos que houve um aumento no número desses grupos a partir de 2007, relacionado ao surgimento da Política Nacional de Educação Especial na Perspectiva da Educação Inclusiva, no ano de 2008 (Casagrande, 2020). 
Os periódicos especializados também se configuram como elementos essenciais à institucionalização do campo acadêmico, como apontam Gómez Campo e Tenti Fanfani (1989) e Suasnábar e Palamidessi (2007). O primeiro voltado à Educação Especial surgiu na UFSM, no ano de 1987: a Revista de Educação Especial (UFSM, 2019).

No ano de 1989, surgiu o Grupo de Trabalho de Educação Especial da ANPEd (GT 15), "dez anos após os primeiros GTs da ANPEd, em reunião na qual organizou-se como os GTs existentes" (Ferreira \& Bueno, 2011, p. 144), porém, antes, em 1990, havia registros de trabalhos e discussões, não sobre deficiência, condutas típicas e altas habilidades, mas sobre meninos de rua, fracasso escolar, problemas específicos de aprendizagem e disciplina. Ainda na década de 1990, foi apresentado um trabalho sobre deficiência e estigma, como parte de uma sessão especial sobre excluídos e estigmatizados (Ferreira \& Bueno, 2011).

O surgimento do GT 15 da ANPEd é considerado um dos marcos do segundo momento de institucionalização do campo acadêmico da Educação Especial no Brasil, que, a partir do ano de 1990, vêm demonstrando constante expansão.

\subsection{TerCeIro MOMENTO: EXPANSÁO do CAMPO ACADÊMICO}

Percebemos que a expansão do campo acadêmico da Educação Especial teve início na década de 1990 com o movimento pró-inclusão e perdura até os dias atuais. Apontamos as evidências de sua expansão: Criação da Revista Brasileira de Educação Especial (RBEE), em 1992; Associação Brasileira de Pesquisadores em Educação Especial (ABPEE), no ano de 1993; Inclusão obrigatória da disciplina de LIBRAS em cursos de magistério, licenciatura e Fonoaudiologia (2005); açóes interinstitucionais e redes de pesquisa (2005); Curso de Graduação em Educação Especial (2008); Curso de Graduação em Educação Especial na modalidade EaD (2010); Cursos de Mestrado Profissional (2013, 2018, 2019 e 2020); Revista Diálogos e Perspectivas em Educação Especial (2014); Revista Educação Especial em Debate (2016) (Casagrande, 2020).

O terceiro momento caracteriza-se pela expansão do campo acadêmico da Educação Especial, a partir do movimento mundial pró-inclusão, que ganhou força no Brasil com a Declaração de Salamanca (1994). A expansão do campo acadêmico sinaliza a ampliação no número de elementos relacionados, ou seja, o aumento na produção de bens acadêmicos relacionados ao campo específico. O contexto histórico-político, social e econômico atua de modo direto no campo acadêmico, pressionando e influenciando seu ritmo de expansão.

Notamos que houve, a partir da década de 2000, aumento na oferta de Programas de Pós-Graduação, em sua maioria Mestrado Profissional. Atualmente, existe um Programa de Pós-Graduação em Educação Especial da UFSCar que trata do campo específico, com oferta de Mestrado e Doutorado e quatro Programas de Mestrado Profissional com temas mais abrangentes, criados: 1. Em 2013, na Universidade Federal Fluminense (UFF), o Curso de Mestrado Profissional em Diversidade e Inclusão (CMPDI); 2. Aprovado em 2018, na Universidade Federal do Recôncavo da Bahia (UFRB), o Programa de Mestrado Profissional denominado "Educação Científica, Inclusão e Diversidade" (PPGCID); 3. No ano de 2019, na Universidade Federal do Rio Grande do Norte (UFRN), o Mestrado Profissional em Educação Especial (PPGEDE); e 4. Em 2020, o Programa de Mestrado Profissional Em Educação Inclusiva em 
Rede (PROFEI). No total são cinco Programas de Pós-Graduação com 14 Linhas de Pesquisa. Importante destacarmos a diferença entre Programas de Mestrado e Doutorado em que o objetivo é a formação de pesquisadores e professores universitários e os Programas de Mestrado Profissional, em que o objetivo é especialmente a formação de recursos humanos para atuação na rede pública e privada de ensino e instituiçóes especializadas (Casagrande, 2020).

As Linhas de Pesquisa nos Programas de Pós-Graduação em Educação constituem-se importante elemento de evidência e expansão do campo acadêmico. Ao buscarmos as Linhas de Pesquisa (LPs) sobre Educação Especial, Inclusão e Educação Inclusiva em Programas de PósGraduação em Educação (PPGEs), nos anos de 2007, 2012 e 2018, notamos que houve um aumento progressivo. No ano de 2007, havia 17 PPGEs ofertando 20 LPs; em 2012, eram 19, com 23 LPs; e, em 2018, totalizaram-se 42 PPGEs com 44 LPs (Casagrande, 2020).

Em relação aos cursos presenciais de Graduação em Educação Especial, há atualmente sete cursos ofertados no Brasil, sendo apenas dois por Universidades públicas (UFSM e UFSCar). Os demais são ofertados por IES privadas, localizadas nas regióes Sul e Sudeste do Brasil. Houve um aumento na oferta de Cursos de Graduação em Educação Especial na modalidade EaD, totalizando 17 Cursos. Somente o Curso de Graduação EaD da UFSM é público e gratuito, o restante vem sendo ofertado por IES privadas, também localizadas nas regiōes Sudeste e Sul (Casagrande, 2020).

Caracterizando a expansão do campo acadêmico, destacamos o surgimento de três periódicos especializados em Educação Especial a partir da década de 1990: 1. Revista Brasileira de Educação Especial (1992); 2. Revista Diálogos e Perspectivas em Educação Especial (2014) e 3. Revista Educação Especial em Debate (2016).

Em relação às redes de pesquisa sobre Educação Especial, notamos as dificuldades de sistematização de dados sobre sua existência. Dessa forma, embora acreditemos na existência de um número maior, elencamos cinco grupos de pesquisadores que desenvolvem açóes interinstitucionais e atividades em rede nacional e internacional. São elas: 1. Observatório Nacional de Educação Especial (ONEESP); 2. Observatório de Educação Especial (ObEE); 3. Rede de Pesquisadores em Educação Especial do Mato Grosso do Sul (REPEEMS); 4. Rede de pesquisadores sobre Financiamento da Educação Especial (FINEESP). O grupo de pesquisadores coordenado pela Professora Doutora Denise Meyrelles de Jesus ${ }^{9}$ atua por meio de açóes interinstitucionais nacionais desde 2005 e em rede internacional desde 2015 (Casagrande, 2020).

Cada um dos momentos apontados pertence a um contexto próprio, razão pela qual recorremos à análise relacional de Pierre Bourdieu para afirmarmos que a Educação Especial, como campo acadêmico, se encontra atrelada a denominaçóes diversas e influenciada pelo campo político do qual recebe influências diretas. Podemos afirmar que Educação Especial constitui-se como um campo acadêmico relativamente consistente, porém restrito para a dimensão do Brasil. Suas instâncias de institucionalização possuem diferentes demarcações histórico-políticas, as quais contam com agentes que produzem e divulgam bens acadêmicos específicos.

\footnotetext{
${ }^{9}$ Informaçóes obtidas por entrevista realizada por meio de transmissão de vídeo feita via aplicativo multiplataforma de mensagens instantâneas no ano de 2020 .
} 


\section{CONSIDERAÇÓES FINAIS}

Diante do contexto exposto, argumentamos que o campo acadêmico da Educaçáo Especial no Brasil caracteriza-se como um campo abrangente e em expansão, mas com paradoxos evidentes. Ao mesmo tempo que pode ser qualificado como abrangente, é insuficiente para a dimensão do país. Está presente, com diferentes intensidades, em todas as regióes do Brasil, mas se restringe a cursos de Graduação e Pós-Graduação em poucas IES públicas. Apresenta uma expansão significativa no âmbito da pesquisa e publicação, mas com um crescimento ainda considerado lento, no que se refere à formação de recursos humanos na Graduação e na Pós-Graduação.

A concentração de bens acadêmicos da Educação Especial, em algumas regióes, e a expansão na rede privada de ensino reproduzem as diferenças regionais e as características do fomento à pesquisa e à Pós-Graduação, demostrando a pouca atenção que a Educação Especial ainda recebe no Brasil. Diante da realidade econômica, política, sociocultural e educacional brasileira, indubitavelmente, o investimento no campo da Educação Especial (pesquisa, formação de professores, Pós-Graduação) é muito aquém do necessário. Alterar esse quadro de concentração e pouca valorização é complexo, pois a luta pela Educação Especial deve ocorrer paralelamente à luta pela educação pública, gratuita e socialmente referenciada em todas as áreas. Reforçamos a necessidade de ampliaçáo de pesquisas acerca dos elementos antecedentes e constituintes do campo acadêmico da Educação Especial no Brasil, a fim de contribuir para o aprofundamento dos estudos sobre esse campo.

Para além da comprovação e da caracterização, esta pesquisa também buscou demonstrar a importância do fortalecimento do campo acadêmico da Educação Especial no Brasil, pois espera-se que os agentes do campo acadêmico atuem na luta contra a invisibilidade e o menosprezo histórico às pessoas com deficiência, por uma Educação Especial Inclusiva no âmbito de uma Educação pública, gratuita e de qualidade.

\section{REFERÊNCIAS}

Almeida, M. A. (2004). Formação do professor para a educação especial: história, legislação e competências. Revista Educação Especial, 24, p. 23-32. http://doi.org/10.5902/1984686X

Bentes, J. A. O. (2010). Formas do trabalho docente em duas escolas especiais de surdos: Estudos históricos e de representaçóes sociais [Tese de Doutorado, Universidade Federal de São Carlos]. Repositório da UFSCar. https://repositorio.ufscar.br/bitstream/handle/ufscar/2868/3215.pdf?sequence=1

Bernardino, L. M. F. (2007). A contribuição da psicanálise para a atuação no campo da Educação Especial. Estilos da clínica, 12(22), 48-67. https://doi.org/10.11606/issn.1981-1624.v12i22p48-67

Bourdieu, P. (1974). A economia das trocas simbólicas. Perspectiva.

Bourdieu, P. (1975). La spécificité du champ scientifique et les conditions sociales du progrès de la raizon. Sociologie et sociétés, 1, 91-118. https://doi.org/10.7202/001089ar

Bourdieu, P. (1986). The forms of capital. In J. G. Richardson (Ed.), Handbook of theory and research for the sociology of education (pp. 241-258). Greenwood Press.

Bourdieu, P. (1989). O poder simbólico. Bertrand Brasil.

Bourdieu, P. (2003). Questóes da sociologia. Fim de século. 
Bourdieu, P. (2004a). Os usos sociais da ciência. Por uma sociologia clínica do campo científico. Editora UNESP.

Bourdieu, P. (2004b). Coisas ditas. Brasiliense.

Bourdieu, P., Chamboredon, J. C., \& Passeron, J. C. (2007). Ofício de sociólogo: metodologia da pesquisa na sociologia. Vozes.

Bourdieu, P., \& Wacquant, L. J. D. (1992). An invitation to reflexive sociology. The University of Chicago Press.

Brizolla, F. (2000). Educação Especial no Rio Grande do Sul: análise de um recorte no campo das politicas públicas [Dissertação de Mestrado, Universidade Federal do Rio Grande do Sul]. Repositório Digital LUME da UFRGS. https://lume.ufrgs.br/handle/10183/79455

Bueno, J. G. S. O. (2004, Novembro 11-14). O aluno como foco de investigaçóes sobre a escola: tendências das dissertaçôes e teses defendidas nos programas de Pós-Graduação em educação - 1981/1998 [Apresentação de Resumo]. Encontro Nacional de Didática e Prática de Ensino - ENDIPE. Curitiba, Paraná, Brasil. http://www.uece.br/eventos/xviiendipe/

Bueno, J. G. S., Braghini, K. M. Z., Munakata, K., \& Meletti, S. M. F. (2018). A produção do conhecimento no Campo da educação especial. Junqueira \& Marin.

Bueno, J. G. S., \& Souza, S. B. (2018). A constituição do Campo da educação especial expressa na Revista Brasileira de Educação Especial-RBEE (1992-2017). Revista Brasileira de Educação Especial, 24(spe), 33-50. https://doi.org/10.1590/s1413-65382418000400004

Carvalho, I. S. M. (1946). A sala ambiente de história na escola secundária para cegos. Revista Brasileira de Estudos Pedagógicos, 7(19), 53-66.

Carvalho, J. C. B. (1988). Origens da ANPEd: de instituída a instituinte. Boletim ANPEd, 8(3-4), 3-7.

Casagrande, R. C. C. (2020). O campo acadêmico da educaçâo especial no Brasil [Tese de Doutorado, Universidade Estadual de Ponta Grossa]. TEDE/IBCIT da UEPG. https://tede2.uepg.br/jspui/ handle/prefix/3169

Castiglioni (1960). O problema da anormalidade na escola primária. Revista do Professor, 59, 39. http://150.162.242.35/bitstream/handle/123456789/130676/Revista\%20do\%20Professor\%20 -\%201960\%20-\%2059.pdf?sequence=1\&isAllowed=y

Ciulla, L. (1947). Menores anormaes do caráter. Revista Brasileira de Estudos Pedagógicos, 10(27), 187205.

Constituição da República Federativa do Brasil (1998). https://www2.senado.leg.br/bdsf/bitstream/ handle/id/518231/CF88_Livro_EC91_2016.pdf

Coppede, A. C., Oliveira, A. K. C., Rosa, F. D., \& Hayashi, M. C. P. I. (2014). Produção científica da Terapia Ocupacional na inclusão escolar: interface com a Educação Especial e contribuiçóes para o Campo. Revista Educação Especial, 27(49), 471-484. http://doi.org/10.5902/1984686X8281

Corbin, J. M., \& Strauss, A. (1990). Grounded theory research. Procedures, canons, and evaluative criteria. Qualitative sociology, 13(1), 3-21. https://doi.org/10.1007/BF00988593

Costa, M. I. L. (1957). A seleção de alunos para as classes especiais. Revista Brasileira de Estudos Pedagógicos, 28(68), 215-217. 
Costa, R. A. S. S. (2014). O campo da educação inclusiva em São José dos Campos - SP: (1989 a 1998). [Dissertação de Mestrado, Universidade Federal de Pernambuco]. Repositório Digital da UFPE. https://repositorio.ufpe.br/handle/123456789/12900

Declaração de Salamanca de princípios, política e prática para as necessidades educativas especiais (1994). http://portal.mec.gov.br/seesp/arquivos/pdf/salamanca.pdf

Diretrizes Curriculares Nacionais da Educação Básica (2013). http://portal.mec.gov.br/docman/julho2013-pdf/13677-diretrizes-educacao-basica-2013-pdf/file

Doria, A. S. (1927). A finalidade educativa (normalidade e anormalidade). Revista Educação, 1(1), 5-15.

Ferreira, R. F., \& Bueno, J. G. S. (2011). Os 20 anos do GT Educação Especial: gênese, trajetória e consolidação. Revista Brasileira de Educação Especial, 7(spe), 143-170. https://doi.org/10.1590/ S1413-65382011000400011

Giúdice, A. (1954). Problemas escolares. Revista do Professor, São Paulo, 20, maio. s/p. https://repositorio. ufsc.br/bitstream/handle/123456789/130694/Revista\%20do\%20Professor\%20-\%201954\%20 $-\% 2020 \cdot$ pdf? sequence $=1$ \&isAllowed $=y$

Glat, R. A. (1995). Integração social dos portadores de deficiências: uma reflexão. Sette Letras.

Glat, R. (2013). Educação inclusiva. Cultura e cotidiano escolar. (2a ed). Letras.

Glat, R., \& Fernandes, E. M. (2005). Da educação segregada à educação inclusiva: uma breve reflexão sobre os paradigmas educacionais no contexto da Educação Especial brasileira. Revista Inclusão, 1(1), p. 35-39.

Gómez Campo, V. M., \& Tenti Fanfani, E. (1989). Universidad y professiones. Crisis y alternativas. Miño y Dávila Editores.

Hey, A. P. (2008a). Fronteira viva: o campo acadêmico e o campo político no Brasil. In M. L. N. de Azevedo (Ed.), Politicas públicas e educação: debates contemporâneos (pp. 217-250). EDUEM.

Hey, A. P. (2008b). Esboço de uma sociologia do campo acadêmico. A educaçâo superior no Brasil. EduFSCar.

Instituto Benjamin Constant (2020). O IBC e a educação de cegos no Brasil. IBC. http://www.ibc.gov. br/a-criacao-do-ibc

Instituto Nacional de Estudos e Pesquisas Educacionais Anísio Teixeira (1944). Bibliografia brasileira de educação: ano de 1944. Revista Brasileira de Estudos Pedagógicos, 4(11), 263-274.

Jannuzzi, G. S. M. (1985). A luta pela educação do deficiente mental no Brasil. Cortez Autores Associados.

Jannuzzi, G. S. M. (2012). A educação do deficiente no Brasil: dos primórdios ao início do século XXI. Autores Associados.

Kirk, S. A., \& Gallagher, J. J. (1987). Education exceptional children. Houghton Miffin Company.

Lei $\mathrm{n}^{\circ}$ 9.394, de 20 de dezembro de 1996. Estabelece as diretrizes e bases da educação nacional. http:// portal.mec.gov.br/seesp/arquivos/pdf/lei9394_ldbn1.pdf

Lei $n^{\circ}$ 13.146, de 6 de julho de 2015. Instituiu a Lei Brasileira de Inclusão da Pessoa com Deficiência (Estatuto da Pessoa com Deficiência). http://www.planalto.gov.br/ccivil_03/_ato2015-2018/2015/ lei/l13146.htm 
Manzini, E. J., Corrêa, P. M., \& Silva, M. O. (2009). Disseminação de conhecimento em educação especial no Brasil: As contribuiçóes da ABPEE. Revista Brasileira de Educação Especial, 15(2), 181196.

Manzini, E. J., \& Glat, R. (2014). Influência das representaçóes sociais do pesquisador na análise de dados de entrevistas: um estudo no Campo da Educação Especial. Education Policy Analysis Archives/Archivos Analiticos de Politicas Educativas, 22(79), 1-18. http://doi.org/10.14507/epaa. v22n79.2014

Masini, E. F. S. (2011). O despontar da Educação Especial na ANPEd. Revista Brasileira de Educação Especial, 17(esp.), 3-16.

Mazzotta, M. J. S. (1982). Fundamentos de Educação Especial. Pioneira.

Mazzota, M. J. S. (1993). Trabalho docente e formação de professores de educação especial. EPU.

Mazzotta, M. J. S. (1994). Políticas de Educação Especial no Brasil: da assistência aos deficientes à educação escolar [Tese de Livre Docência não publicada]. Faculdade de Educação, Universidade de São Paulo.

Mazzotta, M. J. S. (1996). Educação Especial no Brasil: história e políticas públicas. Cortez.

Mazzotta, M. J. S. (2011). Educação Especial no Brasil. História e políticas públicas. Cortez.

Mennucci, S. (1960). A Infância retardatária. Revista do Professor, 51, 12-14. https://repositorio.ufsc.br/ bitstream/handle/123456789/130701/Revista\%20do\%20Professor\%20-\%201960\%20-\%2051. pdf? sequence $=3$ \&isAllowed $=y$

Michels, M. H. (2017). A formação de professores de educação especial no Brasil: propostas em questão. UFSC.

Nota Técnica $\mathrm{n}^{\circ} 4$ de 2014. Orientação quanto a documentos comprobatórios de alunos com deficiência, transtornos globais do desenvolvimento e altas habilidades/superdotação no Censo Escolar. MEC / SECADI / DPEE. http://portal.mec.gov.br/index.php?option=com_ docman\&view=download\&alias=15898-nott04-secadi-dpee-23012014\&category_slug=julho2014-pdf\&Itemid=30192

Okoniewski, H. A. (1957). Educação de débeis mentais. Revista do Professor, 34, 14. https://repositorio. ufsc.br/bitstream/handle/123456789/130583/Revista\%20do\%20Professor\%20-\%201957\%20 $-\% 2034$.pdf? sequence $=1$ \&isAllowed $=y$

Oliveira, I. A., \& França, M. P. S. G. S. A. (2019). Formação de professores em Educação Especial no período da ditadura civil-militar no Estado do Pará. Arquivos Analíticos de Políticas Educativas, 27(68), 1-17. http://doi.org/10.14507/epaa.27.4472

Plata, J. (1948). A capacidade dos cegos para a síntese imaginativa espacial. Revista Brasileira de Estudos Pedagógicos, 7(34), 173-190.

Poiry, J. (1925). O estudo experimental da criança. Revista Escolar, 1(1).

Política Nacional de Educação Especial na Perspectiva da Educação Inclusiva (2008). http://portal.mec. gov.br/index.php?option=com_docman \&view=download $\&$ alias=16690-politica-nacional-deeducacao-especial-na-perspectiva-da-educacao-inclusiva-05122014\&Itemid=30192

Política Nacional de Educação Especial, Equitativa, Inclusiva e ao longo do tempo (2020). https://www. gov.br/mec/pt-br/mec-lanca-documento-sobre-implementacao-da-pnee-1/pnee-2020.pdf 
Portaria $\mathrm{n}^{\circ} 243$, de 15 de abril de 2016. Estabelece os critérios para o funcionamento, a avaliação e a supervisão de instituiçóes públicas e privadas que prestam atendimento educacional a alunos com deficiência, transtornos globais do desenvolvimento e altas habilidades/superdotação. https://www. in.gov.br/materia/-/asset_publisher/Kujrw0TZC2Mb/content/id/2141 3342/do1-2016-04-18portaria-n-243-de-15-de-abril-de-2016-21413232

Possa, L. B. (2016). A emergência da Educação Especial como campo de saber e suas atualizaçóes para o presente. Revista Educação Especial, 29(56), 521-535. https://doi.org/10.5902/1984686X23647

Pourchet, E. (1956). Formação do professor para o ensino em classe especial. Revista Brasileira de Estudos Pedagógicos, 26 (64), 204-209.

Prigol, E. L., \& Behrens, M. A. (2019). Teoria fundamentada. Metodologia aplicada na pesquisa em educação. Educação \& Realidade, 44(3), 1-19. https://doi.org/10.1590/2175-623684611

Puigarri, R. (1903). Cegos e surdos mudos. Revista de Ensino, 1(6).

Rabello, S. (1928). Problemas dos supernormaes. Revista Educação, 5(1).

Resolução no 2, de 11 de setembro de 2001. Diretrizes nacionais para a educação especial na educação básica. http://portal.mec.gov.br/cne/arquivos/pdf/CEB0201.pdf

Resolução $\mathrm{n}^{\circ}$ 4, de 2 de outubro de 2009. Institui Diretrizes Operacionais para o Atendimento Educacional Especializado na Educação Básica, modalidade Educação Especial. http://portal.mec. gov.br/dmdocuments/rceb004_09.pdf

Ribeiro, A. (1942). O Instituto nacional de surdos mudos. Revista do Serviço Público, IV(2).

Rocha Filho, J. S. (1957). Crianças bem-dotadas. Revista Brasileira de Estudos Pedagógicos, São Paulo, 28(68), 215-217.

Romero, A. P. H. (2006). Análise da política pública brasileira para a Educação Especial na década de 1990: configuração do atendimento e atuação do terceiro setor [Dissertação de Mestrado, Universidade Estadual de Maringá]. Repositório da UEM. http://www.ppe.uem.br/SITE\%20PPE\%202010/ dissertacoes/2006-Ana_Paula_Romero.pdf

Santos, F. J. S. (2017). Escolarização e currículo: consideraçôes no campo das deficiências. [Dissertação de Mestrado, Universidade de São Paulo]. Biblioteca Digital da USP. https:/www.teses.usp.br/ teses/disponiveis/48/48134/tde-16102017-111113/pt-br.php

Sassaki, R. K. (1997). Inclusão: construindo uma sociedade para todos. WVA.

Saviani, D. (2012). O Inep, o diagnóstico da educação brasileira e a RBEP. Revista Brasileira de Estudos Pedagógicos, 93(234), número especial, 291-322. https://doi.org/10.24109/2176-6681. rbep.93i234.442

Silva, F. (2011, Maio 16-19). Possibilidades e limites noldo estudo comparado de documentos curriculares: a construçâo da história curricular no campo da Educação Especial (1979 e 1999). [Apresentação de artigo]. 60 Congresso Brasileiro da História da Educação. Vitória, Espírito Santo, Brasil. http:// www.sbhe.org.br/novo/congressos/cbhe6/anais_vi_cbhe/apresentacao.htm

Silva, R. H. S. (2018). Balanço das dissertações e teses em educação especial e educação inclusiva desenvolvidas nos programas de pós-graduação em educação no Brasil. Revista Brasileira de Educação Especial, 24(4), 601-218. https://doi.org/10.1590/s1413-65382418000500009 
Souza, S. B. (2018). Excepcionalidade, deficiência ou necessidades educacionais especiais: o aluno como constituinte do campo da educação especial [Tese de Doutorado, Pontifícia Universidade Católica de São Paulo]. Biblioteca Digital da PUC-SP. https://tede2.pucsp.br/handle/handle/20932

Souza Pinto, N. (1933). O Ensino dos anormais. Revista de Educação, 3(3), 36-38. https://repositorio. ufsc.br/xmlui/handle/123456789/131299

Souza Pinto, N. (1935a). A educação dos anormais e dos débeis mentais. Revista do Professor, 2(10), 29. https://repositorio.ufsc.br/xmlui/bitstream/handle/123456789/130679/Revista\%20do\%20 Professor\%20-\%201935\%20-\%2010.pdf?sequence=1\&isAllowed=y

Souza Pinto, N. (1935b). Os anormaes escolares. Revista do Professor, 8-9. https://repositorio.ufsc.br/ xmlui/bitstream/handle/123456789/130576/Revista\%20do\%20Professor\%20-\%201935\%20 -\%2003.pdf?sequence= 1 \&isAllowed $=y$

Souza Pinto, N. (1935c). A educação dos anormaes e dos debeis mentaes. Revista de Educação, 11-12(1112), 30-36. https://repositorio.ufsc.br/bitstream/handle/123456789/128340/Revista\%20de\%20 Educa\%c3\%a7\%c3\%a3o\%20-\%201935\%20-\%2011\%20e\%2012.pdf?sequence=1 \&isAllowed=y

Souza Pinto, N. (1937). Evolução histórica da educação dos anormaes (incompleto). Revista do Professor, $4(19)$.

Souza Pinto, N. (1950). Educação de crianças anormais. Revista do Professor, 1(4), 20. https://repositorio. ufsc.br/bitstream/handle/123456789/130688/Revista\%20do\%20Professor\%20-\%201950\%20 -\%2004.pdf?sequence= 1 \&isAllowed $=y$

Souza Pinto, N. (1959). O Ensino para débeis mentais. Revista do Professor, 1(44). https://repositorio. ufsc.br/bitstream/handle/123456789/130616/Revista\%20do\%20Professor\%20-\%201959\%20 $-\% 2044$.pdf? sequence $=1$ \&isAllowed $=y$

Stremel, S. (2016). A constituição do Campo acadêmico da política educacional no Brasil. [Tese de Doutorado, Universidade Estadual de Ponta Grossa]. TEDE/IBCIT da UEPG. https://tede2.uepg. br/jspui/handle/prefix/1209

Stremel, S. (2017). Aspectos teórico-metodológicos para a análise da constituição do Campo acadêmico da política educacional no Brasil. Revista de Estudios Teóricos y Epistemológicos en Política Educativa, 2, 1-14. https://doi.org/10.5212/retepe.v.2.001

Suasnábar, C., \& Palamidessi, M. (2007). Notas para uma história del campo de producción de conocimientos sobre educación em la Argentina. In M. Palamidessi, C. Suasnábar, \& D. Galarza (Eds.), Educación, conocimiento y política. Argentina, 1983-2003 (pp. 39-63). Manantial.

Teixeira, A. S. (1968). Educação é um direito. Companhia Editora Nacional.

Tello, C. G. (2013). El Campo teórico de la política educacional. Modelos, abordajes y objetos de estudio. Jornal de Políticas Educacionais, 7(14), 62-75. http://doi.org/10.5380/jpe.v7i14.38225

Universidade Federal de São Carlos (2019). Histórico. Recuperado em 20 de janeiro de 2020 de http:// www.ppgees.ufscar.br/programa/historico

Universidade Federal de Santa Maria (2019). História. Recuperado em 21 de janeiro de 2020 de https:// www.ufsm.br/cursos/graduacao/santa-maria/educacao-especial/historia/

Recebido em: 19/08/2020

Reformulado em: 18/10/2020

Aprovado em: 21/10/2020 
CASAGRANDE, R.C. \& MAINARDES, J. 